$$
\text { 신생아 청력 선별검사 }
$$

부산대학교 의과대학 이비인후과학교실

이 일 우

\title{
Universal Newborn Hearing Screening, UNHS
}

\author{
Il-Woo Lee, MD
}

Department of Otolaryngology, College of Medicine, Pusan National University, Busan, Korea

\section{서 론}

소아는 말을 본격적으로 하기 시작하는 24 개월에 이 르는 동안 언어나 환경음을 지속적으로 청취하여야 청 각신경전달계가 정상적으로 성숙하게 된다. 만일 이 시 기에 소리자극이 주어지지 않는다면 언어발달이 지연되 고 지능의 성숙이나 사회적 적응, 학습성취에서 막대한 손실을 가져오게 된다. 불행하게도 신생아에 대한 청력 선별검사가 이루어지지 않는 시점에서 대부분의 선천성 난청환자는 생후 24 개월이 지나야 인지가 되고 병원을 찾아 난청으로 진단받기까지는 이보다 더 오랜 시간이 걸리기도 한 실정이다. 소아의 청력선별검사의 목적은 생후 3 개월 이전에 선천성난청을 가진 소아를 찾아내어, 생후 6 개월 이내에 적절한 조치를 취하는 것이다. 6 개월 이전 진단되어 조치를 취한 환아에서는 거의 정상적인 언어 발달을 보이는데, 이는 소아의 언어습관이 주로 6 개월 이후 발달되기 때문이다. 선천성 난청의 조기발견 에 대한 필요성은 1960년대 중반부터 꾸준히 제기되어 왔으나 유소아에서의 객관적인 청력검사 방법이 개발되 지 않아 비 현실적인 것으로 생각되어 널리 활용되지는 못하였다. 최근 이러한 문제점이 극복되어 전세계적으로 구체적인 실현을 위한 노력들이 전개되고 있다.

교신저자 : 이일우, 602- 739 부산광역시 서구 아미동 1가 부산대학교 의과대학 이비인후과학교실

전화 :(051) 240- 7536. 전송 : (051) 246- 8668 E- mail : entgate@pusan.ac.kr

\section{난청의 빈도}

일반적으로 출생아 10 명당 1 명은 난청의 고위험군에 속하며, 200명당 1명은 각종 난청으로, 그리고 500 1000 명당 1 명은 양측 난청이며, 이중 $10 \%$ 는 고도난청 아로 태어나고 감각신경성난청의 약 $5.3 \%$ 가 선천성 또 는 유전성난청이다. 1993년 미국 국립보건원의 보고에 의한 선천성 난청의 비율은 신생아 1,000 명당 1 명 정도 이다. 통계청의 통계에 의하면 2002년 출생한 신생아의 수는 약 57만명 정도이며 따라서 매년 570명 정도가 난 청을 가지고 태어난다고 추산할 수 있다. 이는 현재 모든 신생아에 대해 선별검사가 이루어지고 있는 갑상선기능 저하증이나 페니케토산뇨증 등의 5 가지 대사질환의 빈 도보다 훨씬 높은 발병률이다. 또한 난청을 조기에 발견 하지 못함으로써 적절한 재활시기를 놓치게 되어 심각 한 언어장애를 일으키고 이로 인한 학습장애 등으로 사 회구성원으로서 적절한 기능을 발휘할 수 없게 된다. 선 천성 대사장애의 경우와 마찬가지로 이러한 장애는 조 기발견 및 조기재활을 통해 충분히 예방될 수 있기 때 문에 $100 \%$ 선별검사를 통하여 난청아를 조기 발견해야 하는 것이다.

\section{역사적 고찰}

1960년대초 Marion Downs가 난청의 조기발견과 조 기 치료의 중요성을 강조하며 행동반응청력검사를 통한 
신생아 청력선별검사를 제안하였으나 청력을 정확하게 평가하기에는 한계가 있었다. 1970년대 청성뇌간반응검 사가 개발되면서 신생아에대한 객관적 청력검사가 활발 하게 이루어지기 시작했지만 $\mathrm{ABR}$ 은 검사하기가 복잡하 여 훈련된 검사자가 있어야 한다는 점과 많은 시간이 들 고 검사료도 비싸 선별검사로서의 기능을 할 수 없었다. 신생아에 대한 선별청력검사는 1978년 이음향방사가 개 발되면서 비교적 간단한 방법으로 객관적인 청력검사가 가능하게 되었고 1980년대 후반에 자동화된 ABR(automated $\mathrm{ABR}, \mathrm{AABR}$ )이 소개되어 보다 정확하면서 간 편하게 검사가 가능하게 되었다. ${ }^{1)}$

1982년 미국의 Joint Committee on Infant Hearing $(\mathrm{JClH})$ 에서 처음으로 청력선별검사가 필요한 난청 고 위험군 신생아에 대한 guideline을 제시한 이래 개선을 거쳐왔다. 1990년 JCIH는 난청의 고위험군으로 감각신 경성난청의 가족력이나 자궁내 감염이 있는 경우, 교환 수혈이 필요한 고빌리루빈혈증, 항생제 이뇨제 등의 이 독성약물을 사용한 경우, 세균성뇌막염을 않은 경우, 출 생시 A pgar score가 1분에 4점, 5분에 6점이하이거나 5 일이상 인공호흡기를 사용한 경우, 감각신경성난청이 나 전음성난청유발증후군 등이 있는 경우로 분류하여 이 들은 난청에 대한 조기 검사를 반드시 실행할 것을 제안 하였다. 그러나 실제로 선천성난청의 약 절반은 이들 고 위험군이 아닌 정상신생아에서 발견되는 것으로 알려져 고위험군 뿐 아니라 모든 신생아에서 조기검사를 실시 하도록 권장하게 되었다.

\section{조기 진단 검사법}

난청의 진단을 위한 청력검사방법은 크게 행동반응검 사와 객관적인 측정이 가능한 생리적 검사로 나누어진 다. 유소아에서 시행가능한 행동반응검사방법에는 생후 6 개월 정도까지의 신생아에게 이용할 수 있는 행동관찰 청력검사(behavioral observation audiometry), 6개월 에서 2.5개월사이의 아이에게 적용되는 시각적으로 강화 된 행동관찰 청력검사(visual reinforced audiometry), 그리고 3 5세의 소아에게 가능한 유희청력검사(condition play audiometry) 등이 있다. ${ }^{1)}$ 하지만 이들 검사 는 객관적이지 않으며 선별검사에서의 가장 중요한 개
념인 난청의 소기발견을 위한 검사로는 문제가 있어 현 재는 선별검사의 도구로 적절한 것이 아니라고 인정되 고 있다.

청력 선별검사 방법으로 적합하려면 검사방법이 간단 하면서도 감수성과 특이성이 높아야 한다. 검사방법은 궁극적으로 훈련받은 청각사가 아닌 신생아실에서 종사 하는 사람이 쉽게 검사할 수 있어서 신생아가 병원에서 퇴원하기 전에 시행이 가능해야 한다. 검사결과에 대해 객관적인 기준이 적용될 수 있고 비침습적이어야 하며 검사비용이 선별검사라는 의의에 맞도록 적절한 수순이 어야 한다. 신생아가 퇴원하기 전에 검사시행이 가능해 야 한다. 현재 선별검사로서 이러한 조건에 적합한 검사 방법은 유발이음향방사 Evoked otoacoustic emission, $\mathrm{EOAE}$ ) 와 자동화 청성뇌간반응(Automated auditory brainstem response) 이 있다. ${ }^{1) 2}$

\section{유발이음향방사}

$\mathrm{OAE}$ 는 1978년 Kemp에 의해 처음으로 인체에서 측 정되었다. $\mathrm{EOAE}$ 는 어떤 자극음에 대하여 외유모세포에 서 발생하는 음향에너지의 진동파를 외이도에서 측정함 으로써 와우의 정상적인 기능 여부를 알아보는 검사법 이다. $\mathrm{EOAE}$ 는 빠른 검사가 가능하고 전극이 필요없고 따라서 전기자극에 무관하여 중환자실내에서 검사해도 오류가 적은 등의 장점이 있어 검사가 용이하여 선별검 사로서 가장 적합한 방법이라 할 수 있다. 클릭유발이음 향방사 (T ransient EOAE, T EOAE) 와 변조이음향방사 (Distortion product $\mathrm{OAE}, \mathrm{DPOAE}$ ) 의 두가지 검사법 이 있다. 청력역치를 정확히 검사할 수는 없지만 회화음 역의 청력역치가 30 40 dB를 넘으면 나타나지 않아 $\mathrm{OAE}$ 에 반응이 없는 경우 청력소실정도가 $30 \sim 40 \mathrm{~dB}$ 이 상이라고 진단할 수 있다. 외부소음이나 외이 및 중이의 상태에 따라 영향을 받는 단점이 있으나 검사시기를 생후 24시간이후로 하고 숙련된 검사자에 의해 검사하거나 주위의 소음을 줄임으로서 위양성율을 낮출 수 있다. ${ }^{1{ }^{13)}}$

\section{청성뇌간반응}

$\mathrm{ABR}$ 은 신생아와 소아의 청각시스템을 평가하는데 있 
어 가장 객관적인 방법이다. 사람에서의 A BR은 1971 Jewett와 Williston가 최초로 시행하였다. 클릭음을 주 어 뇌간까지의 청신경의 활동성을 측정한다. 반응은 자 극후 5 $6 \mathrm{msec}$ 내에 나타나며 major peaks가 연속적 으로 나타나는 파형을 띤다. 일반적으로 ABR은 1000 $4000 \mathrm{~Hz}$ 영역에 대한 정보를 제공하는데 실제적으로 청 력검사라기 보다는 청신경이 뇌간에 이르는 경로까지의 신경의 연속성을 특정하는 것이라 할 수 있다. Conventional ABR은 상대적으로 비싸고 검사에 시간이 걸리며, 숙련된 검사자가 필요하고 결과 판독도 어려워 선별검 사로서는 부적합하여 automated $\mathrm{ABR}(\mathrm{AABR})$ 이 개발 되었다.

Natus Medical Incorporated 사가 1985년 상업적 으로 유용한 $\mathrm{AABR}$ 인 $\mathrm{ALGO}{ }^{\circledR}$ 를 개발함으로서 $\mathrm{ABR}$ 에 의한 청력선별검사의 시대가 열리게 된다. $A L G O{ }^{\circledR}$ 에서 이용되는 방법은 likelihood ratio(LR) 이라는 척도를 통 계적인 비교방법으로 이용한다. 즉 정상신생아에서 구한 청성뇌간반응의 표준치와 검사를 받는 신생아의 파형을 비교하여“ pass” 혹은" refer”로 표시해 줌으로서 비전 문가라도 검사결과의 판정을 간단히 할 수 있게 해 준다. pass는 수집된 data가 소리에 대한 반응과 단순한 noise나 noise와 혼합된 반응, 반응이 없는 경우와 구별 이 가능하다는 의미로서 신뢰도는 $99.8 \%$ 이상이다. refer 는 수집된 data가 반응이 없는 경우와 구별이 안된다는 것을 의미하며 refer가 나온 환아는 선별검사 시스템에 의해서 3 개월 내에 재검사하여 정확한 진단을 받고 재 활 프로그램에 참여할 수 있다.

\section{장 비}

최근의 선별검사기기는 휴대가능하고 결과를 해석할 필요없이 ' pass' 혹은' refer'로 바로 표시해주는 자동 화된 장비가 보급되고 있다.

현재 상용화된 검사장비는 $\mathrm{EOAE}$ 를 이용한 AudioPath (Wellh Allyn), AABR을 이용한 ALGO $3^{\circledR}$ (Natus), 두가지 검사를 같이 할 수 있는 AUDIO screener ${ }^{\circledR}$ (GSI), A Bear ${ }^{\oplus}$ (Bio- logic), A ccuScreen ${ }^{\oplus}$ (Madsen) 등이 있다.

\section{조기진단 프로그램}

1993년 미국 NIH에서는 OAE와 ABR의 2단계 선별 검사를 시행할 것을 권장하였고 영유아기에 걸쳐 지속 적인 관찰을 통해 적절한 중재와 재활 프로그램을 마련 해야 한다고 하였다. ${ }^{2)}$

또한 최초의 검사는 신생아 출생후 입원기간 동안에 시행하도록 권장하고 있다. 선별검사 프로그램은 검사순 서의 차이에 따라 정상 신생아와 중환자실의 신생아를 분리하여 별도의 조기진단 프로그램을 적용하는 것이 합 리적이다. 정상신생아의 경우 입원중에 $\mathrm{EOAE}$ 를 실시하 여 정상인 경우 선별검사 프로그램에서 제외시키고 이상 이 있는 경우 AABR을 실시한다. 여기서 또 이상이 발 견되면 1 개월후 외래에서 재검사를 시행하고 이상이 발 견되면 정밀검사에 들어간다Fig. 1). 입원중 EOAE에 통과하여 정상이라고 판정된 경우에도 위험인자가 있는 경우에는 6 개월째 재검사를 시행하여야 한다. 또한 진 행성 혹은 지연성 난청의 위험이 있는 영유아는 말언어 발달에 가장 중요한 시기인 만 3세까지는 6 개월 간격으 로 정기적인 검사를 받아야 한다.

중환자실 신생아의 경우에는 난청의 빈도가 정상신생 아보다 높기 때문에 다른 프로그램을 적용한다. 와우는 정 상이면서 청신경에 병변이 있는 청신경증의 경우 $\mathrm{EOAE}$ 에서는 정상소견을 보이기 때문에 $\mathrm{ABR}$ 을 먼저 시행하 여야 하며 통과하지 못할 경우 $\mathrm{EOAE}$ 를 퇴원전에 시행

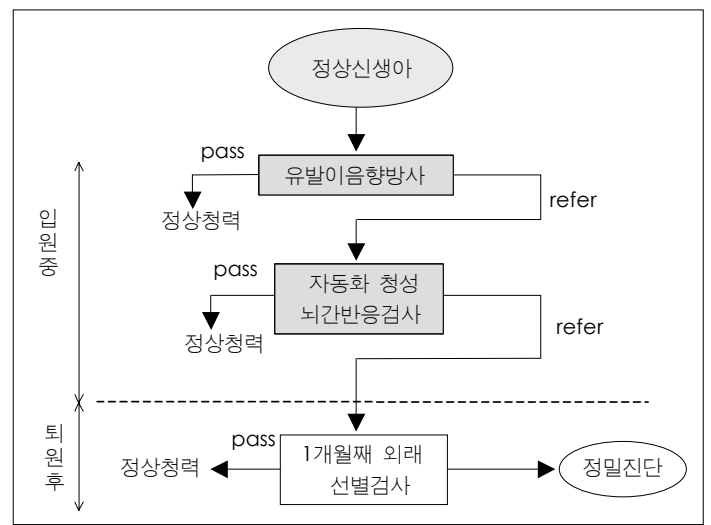

Fig. 1. 정상 신생아의 신생아 난청 조기진단 프로그램. 
하고 결과에 따라 1 개월째 외래에서 재검사를 실시한다 (Fig. 2) .

\section{국내에서의 신생아청력선별검사}

국내의 신생아 청력선별검사는 1997년 단국대에서 TEOAE를 이용하여 1145 명의 신생아를 선별검사하여 refer 된 157예(14\%)와 9예(0.8\%)의 감각신경성 난 청을 보고하였고 1999년 아주대에서 1459예, ${ }^{4)} 2000$

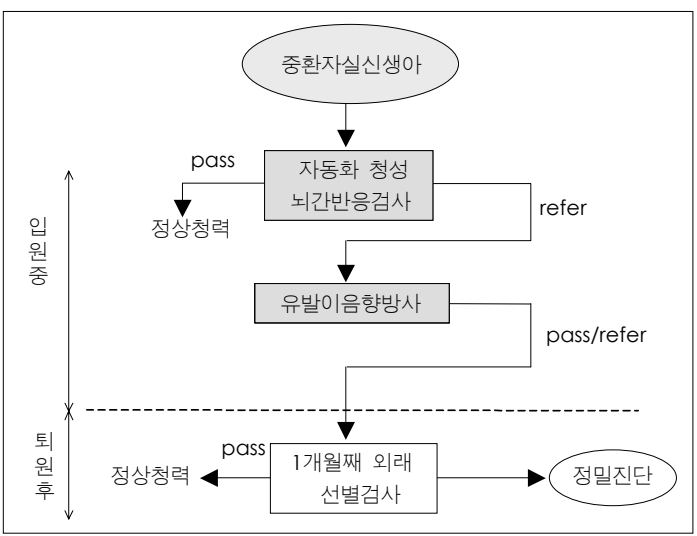

Fig. 2. 중환자실 신생아의 신생아 난청 조기진단 프로그램.
년 서울대에서 DPOAE를 이용하여 72예(144귀) 의 선 별검사를 시행하였다. ${ }^{5)}$ 2002년 동아대에서 543예를 검사하여 $2.8 \%$ (15예) 의 refer rate를 보고하였다. 현 재는 일부 대학병원에 검사를 시행하고 있으나 아직까 지 모든 신생아를 대상으로 국가적인 차원에서 선별검 사할 수 있는 체제가 확립되어 있지 않은 상태이다. 이 는 선별검사의 중요성에 대한 인식이 사회전반에 있어 부족한 것이 원인인데 이의 해결을 위해서는 우선 부모 와 의사가 이러한 필요성을 잘 인식하고 확대시켜 나가 야 할 것이다. 무엇보다도 모든 장애인을 사회가 책임지 려하는 성숙한 의식을 가져야 한다.

선별검사가 신생아 $100 \%$ 에서 시행되지 않고 있는 이유는 부모나 의사의 인식부족에서도 그 이유를 찾을 수 있으나 무엇보다 가장 큰 이유는 검사에 소요되는 비용을 부담하려는 노력이 없기 때문이라 할 수 있다. 미 국의 유타대학이 1998년과 1999년 조사한 설문조사에 의하면 청력선별검사를 전체적으로 실시하는 데 가장 큰 장애는 역시 비용부담이었고 그다음이 병원의 의지가 없거나 검사기기의 가격이 너무 비싸기 때문으로 나타 났다 ( T able 1). ${ }^{6)}$

문 등에 의하면 국내에서 1 명의 신생아에 대하여 청

Table 1. The obasacles to implementing statewide UNHS programs ( Utah State University)

\begin{tabular}{|c|c|c|c|c|}
\hline \multirow{3}{*}{ Potential obstacles } & \multicolumn{2}{|c|}{1999 Results } & \multicolumn{2}{|c|}{1998 Results } \\
\hline & \multicolumn{2}{|c|}{$n=47$} & \multicolumn{2}{|r|}{$\mathrm{n}=35$} \\
\hline & Rank & Mean rating* & Rank & Mean rating* \\
\hline $\begin{array}{l}\text { Unwillingness of third-party payers to reimburse for } \\
\text { newborn screening }\end{array}$ & 1 & 3.07 & 1 & 3.5 \\
\hline Hospitals are not willing to add another procedure & 2 & 2.94 & 3 & 2.9 \\
\hline Equipment is too expensive & 3 & 2.84 & 2 & 3.32 \\
\hline $\begin{array}{l}\text { Lack of appropriate hearing diagnositc services for } \\
\text { infants and yount children }\end{array}$ & 4 & 2.74 & 5 & 2.7 \\
\hline False -alarm rate are too high & 5 & 2.56 & 4 & 2.71 \\
\hline Short hospital stays for newborn and mothers & 6 & 2.5 & 6 & 2.58 \\
\hline Lack of appropriate early intervention services in the state & 7 & 2.34 & 8 & 2.21 \\
\hline Physician's opposition to hospital-based screening & 8 & 2.22 & 7 & 2.32 \\
\hline Screening procedure are too complex and time-consuming & 9 & 2.13 & 10 & 2.02 \\
\hline $\begin{array}{l}\text { Research on the effectiveness and feasibility of } \\
\text { newborn hearing screening not convincing enough }\end{array}$ & 10 & 1.97 & 9 & 2.11 \\
\hline The benefits of early identification have not been proven & 11 & 1.81 & 11 & 1.73 \\
\hline Parents are opposed & 12 & 1.48 & 12 & 1.72 \\
\hline
\end{tabular}

*Rating on a 5 point scale

(Definitely not an obstacle) 12345 ( An extremely serious obstacle) 
력선별검사를 할 때 그 비용은 약 8,000 원이고, 1 명의 선청성 난청 환아를 선별하는데 약 485만원이 필요하다 고 하였다. 이는 앞서 설명한 조기진단의 중요성, 필요성 을 고려하거나 언어습득시기 이후에 발견된 난청환자를 적절한 중재를 통하여 정상적인 언어활동을 가진 사람 으로 재활시키기까지 들어갈 비용에 비하면 비용 효율 면에서도 선별검사는 꼭 시행되어야 할 것이다. ${ }^{7)}$

\section{본원에서의 신생아 선별 청력검사}

본원에서는 자동화된 유발이음향방사 검사로 선별검사 를 시행하고 있다. 이 검사에 통과하는 정상신생아는 검 사에서 제외시키고 중환자실 신생아의 경우는 통과하더 라도 1 개월후 외래에서 AABR 검사를 시행하도록 하고 있고 $\mathrm{EOAE}$ 에 통과하지 못하거나 난청이 강력하게 의심 되는 경우는 퇴원전에 $\mathrm{AABR}$ 을 시행하는 것을 원칙으로 하고 있다. $\mathrm{AABR}$ 을 중환자실에서 첫 검사로 시행하지 못하는 이유는 AABR이 주변소음이나 환아의 수면상태 에 영향을 많이 받아 검사에 시간이 많이 걸리기 때문 인데 이 또한 점차적으로 시행하려 하고 있다. 의료보험 의 적용이 되지 않아 검사전 부모에게 충분한 설명을 하 여 동의를 받아 검사를 시행하며 이를 위해 별도의 설명 서와 동의서를 작성하여 이용하고 있다 별지 참조).

\section{결 론}

현재 국내의 의료보험 상황을 고려할 때 정상 신생아 에 대한 청력 선별검사는 비용부담 면에서 검사자와 환 자의 부모 모두가 부담스러운 것이 사실이다. 선별청력 검사는 난청의 빈도를 감안하고 조기진단으로 얻을 수 있는 효과, 사회의 복지비용 감소 등의 경제적인 측면에 서도 모든 신생아에서 시행하여야 하며 이는 이런한 검
사와 관련된 이비인후과, 소아과 의사 및 국가와 국민 모 두의 긴밀한 협조를 통해 발전되어 나가야 할 것이다. 모 든 신생아에서 $100 \%$ 검사가 시행되려면 국가적인 차원 에서 사업이 이루어져 체계적인 관리가 되어야 할 것이 다. 또한 난청을 발견하는 것 뿐 아니라 청각재활 프로그 램과 연결되어야 실제로 환자에게 도움을 줄 수 있고 사 회복지에도 기여할 수 있을 것이다. 이를 위해서는 인식 의 전환과 함께 이에 소용되는 비용의 확보가 절대적으 로 필요하다.

중심 단어 : 신생아 청력 선별검사 이음향방사 청성뇌 간반응.

\section{REFERENCES}

1) Norton SJ, Gorga MP, Widen JE, Folsom RC, Sininger Y, Cone-Wesson BV, et al. Identification of Neonatal Hearing Impairment: Summary and Recommendations. Ear \& Hearing 2000;21:529-35.

2) Norton SJ, Gorga MP, Widen JE, Folsom RC, Sininger Y, Cone-Wesson BV, et al. Identification of Neonatal Hearing Impairment: Evaluation of Transient Evoked Otoacoustic Emission, Distortion Product Otoacoustic Emission, and Auditory Brain Stem Response Test Performance. Ear \& Hearing 2000;21:508-28.

3) Berg AO (U.S. Preventive Service Task Force). Newborn Hearing Screening: Recommendations and Rationale. AJN 2002;102:83-95.

4) Moon SK, Park HJ, Park MS, Kim YJ, Choung YH, Park $\mathrm{KH}$. Results and cost effectiveness of newborn hearing screening program in Ajou University Hospital. Korean $J$ Otolaryngol 2003;45:1052-6.

5) Chang SO, Oh SH, Koo JW, Lim DH, Hwang CH, Kim CS, Choi JH. Distortion product and spontaneous otoacoustic emissions in normal neonates. Korean J Otolaryngol 2000; 43(4):363-8.

6) Keren R, Helfand M, Homer C, McPhillips H, Lieu TA. Projected cost-effectiveness of statewide universal newborn hearing screening. Pediatrics 2002;110:855.

7) Widen JE, Bull RW, Folsom RC. Newborn hearing screening What it means for providers of early intervention services. Infant and Young Children 2003;16:249-57. 


\section{$\square$ 부 록 $\square$}

〈부산대학교병원에서 사용중인 screening 동의서〉

\section{신생아 청력 선별검사 동의서}

병력지 번호 :

아기이름 :

생년월일 :

부모이름 : 부 -

모 -

주소 :

전화번호 :

1. 혈연관계가 있는 친척중에 어릴때부터 생긴 청력손실이나 청력감퇴가 있었던 사람이 있습니까?

$\square$ 예 $\square$ 아니오

있다면 누구입니까?
$\square$ 아버지
$\square$ 어머니
$\square$ 형제
$\square$ 자매
$\square$ 조부모
$\square$ 삼촌
$\square$ 사촌 $\square$ 기타

2. 임신중 아래의 질환을 않은 적이 있습니까 ? $\square$ 예 $\square$ 아니오
$\square$ 폐렴
$\square$ 간염
$\square$ 풍진 뇌막염
$\square$ 거대세포바이러스감염
$\square$ 단순포진
$\square$ 매독
$\square$ 톡소포자충증( T ox oplasmosis)
$\square$ 기타

3. 가족중 누구라도 청력소실과 관련되는 증후군이나 질환으로 진단받은 일이 있습니까?

$\square$ 예 $\square$ 아니오

있다면 간단히 설명해 주세요.

나는 청력선별검사의 중요성과 방법, 장비, 비용 등에 대해 충분한 설명을 듣고 부산대학교병원에서 내 아기의 청력선별검사에 자발적으로 동의합니다. 또한 선별검사결과를 다른 연구소, 연구단체와 공유하 거나 내용을 출판하는 일에도 동의합니다.

성 명 :

서 명 :

날 짜 : 200

부산대학교병원 이비인후과 
안녕하십니까? 이비인후과입니다.

먼저 귀여운 아기의 탄생을 진심으로 축하드립니다.

현재 전세계적으로 관심이 되고 있는 신생아의 선별청력검사에 대하여 안내해드리겠습니다.

선별청력검사란 모든 신생아에서 검사를 시행하는 것을 말합니다. 이는 발병빈도가 낮더라도 만일 발 병했을 경우 아이에게 치명적인 장애를 초래할 수 있는 질환에 대하여 미리 그 발병유무를 알아보는 것 입니다. 참고로 선천성 대사질환 즉 선천성 갑상선 기능 저하증 이라든지 페닐케토산뇨증(PKU) 등의 질환은 우리나라에서도 모든 신생아에게 선별검사 screening test) 를 시행하여 신체나 지능이 정상적 으로 발달할 수 있도록 하고 있습니다.

난청은 이러한 선천성 대사질환보다 그 유병율이 높음에도 불구하고 현재 선별검사는 시행되지 않고 있습니다. 전세계적으로 신생아 천명 당 대략 1.5 3명의 발현률을 보이며 우리나라의 경우 2002년 통 계청의 통계에 의한 56 만명의 신생아를 근거로 하면 매년 약 600 명에 달하는 난청신생아가 발생하고 있다고 추정해 볼 수 있습니다.

선천성 대사질환의 경우와 마찬가지로 난청도 신생아의 특성상 조기에 발견하기가 어렵습니다. 일반 적으로 3 개월까지는 큰 소리에 가끔 놀라는 것 외에 청력이 있음을 알 수 있는 방법이 없고 6개월 정 도 되면 소리나는 방향으로 돌아본다고 하지만 그것만으로 정상청력을 가졌다고 확인할 수 없습니다. 만 12 개월 경에는 엄마, 아빠 외의 의미 있는 말을 한다고 하지만 개인적인 차이가 있고 보통은 2 세 이상이 되어야 언어발달 지연을 호소하여 병원을 찾게 되고 청력에 이상이 있음을 발견하게 됩니다.

그러나 언어의 습득은 반복학습에 의하며 출생 후 24 개월까지의 반복적인 듣기가 언어능력의 형성과 정에 필수적이라 할 수 있습니다. 이 시기에 청각자극이 주어지지 않으면 그후에 자극이 주어져도 언어 습득이나 지능발달에 장애를 주게 됩니다. 신생아는 말을 배우는 데 천부적인 재능을 가지고 있습니다. 성인의 경우 언어습득능력은 신생아 혹은 소아보다 현저히 떨어지는데 성인이 다른 언어환경에서 2년 정도 생활을 한다해도 신생아가 2 년간 언어를 배우는 것보다 능률은 떨어집니다. 따라서 신생아에서 청 력선별검사는 모든 신생아에서 필수적으로 해 주어야 합니다.

이에 본원에서는 최신 개발된 선별청력검사기기를 도입하여 본원에서 출생하는 모든 신생아에게 검 사를 시행하고 있습니다. 이는 기존의 장비와는 달리 최소의 장비로 간단히 시행할 수 있고 아이가 자 는 동안 시행할 수 있습니다.

비보험으로 $\quad$ ) 원 정도의 비용이 추가됩니다.

1. 출생을 축하합니다.

2. 신생아 청력선별검사는 모든 신생아에서 실시하며, 검사를 통해 청력감퇴여부를 조기에 발견하여 야 조기치료가 가능합니다.

3. 검사장비는 최신개발제품으로 검사가 간단하며 아기가 자는 동안 시행할 수 있습니다.

4. 아직 보험의 적용이 되지 않아 ( ) 원 정도의 추가비용이 비보험으로 추가됩니다.

부산대학교병원 이비인후과 